\title{
Defining Existence Presentism
}

\author{
Jonathan Charles Tallant
}

Received: 8 February 2012/Accepted: 30 August 2012/Published online: 19 June 2013

(C) The Author(s) 2013. This article is published with open access at Springerlink.com

\section{Introduction}

In this paper I argue in favor of a new definition of presentism that I call 'existence presentism' (EP). Typically, presentism is defined as the thesis that 'only present objects exist', or 'nothing exists that is non-present'. ${ }^{1}$ I assume these statements to be equivalent. I call these statements of presentism 'conventional presentism' (CP). First, in Sect. 2, I rehearse arguments due to Meyer (2005) that purport to show that presentism is not adequately defined as CP. In Sects. 2.1-2.4 I show that considerations of the sort raised by Meyer infect attempts to define presentism, due to Crisp (2004a, b), Stoneham (2009), Crisp (2005a) and Sider (2006). Thus the first half of the paper is constituted by a negative project that looks to show how extant definitions of presentism fail. In the second half of the paper, I continue in the negative theme in Sect. 3, before laying out (EP) and demonstrating that it solves the problems faced by $\mathrm{CP}$ and offering explanations of how to make sense of certain key notions that lie at the heart of EP. I conclude that EP is preferable to $\mathrm{CP}$.

\section{Meyer's Complaint}

Meyer begins by noting that there are two obvious and initially intuitive ways to understand presentism.

P1) Nothing exists now that is not present

P2) Nothing exists temporally that is not present

\footnotetext{
${ }^{1}$ See, inter alia, Markosian (2004).
}

J. C. Tallant $(\bowtie)$

Department of Philosophy, University of Nottingham, Nottingham NG7 2RD, UK

e-mail: Jonathan.tallant@nottingham.ac.uk 
According to Meyer, to exist 'temporally' is to exist in time; in more perspicuous terms, to 'exist temporally' is to have existed, exist now, or to be going to exist.

Meyer then makes the following complaint. P1 is trivially true. Of course nothing exists now that is not present. No-one denies this. Even Eternalists endorse P1. So $\mathrm{P} 1$ is not a definition of presentism. That leaves P2 as our definition of presentism. But P2 is false. It is clearly true that Julius Caesar did exist. And, if Caesar did exist, then Ceasar exists temporally. So Caesar does not exist now, but does exist temporally. Thus, it is not the case that 'nothing exists temporally that is not present'. P2 cannot be our definition of presentism.

The natural response to Meyer is to insist that there is a sense in which we can use the verb 'exists' — exists simpliciter, perhaps - that avoids this objection. But this raises the question as to what, precisely, is meant by 'exists simpliciter'. Meyer (2005: 215) reasons as follows. If $a$ exists simpliciter, then it exists either in the actual world or in some merely possible world. And, if $a$ exists in the actual world, then it does so by existing temporally; by having existed, existing now, or being such that it is going to exist. Thus, if we are to specify the meaning of 'exists simpliciter', we must take it to mean either 'outside time', but somehow still in the actual world, or else at another possible world altogether. But as Meyer (2005: 215) points out, neither of these readings of 'exists simpliciter' gives us anything that resembles a definition of presentism. The two additional options generated are:

Nothing exists outside time that is not present.

Nothing exist in other possible worlds that is not present

Neither of these obviously captures what the presentist has in mind when they try to define presentism with $\mathrm{CP}$.

\subsection{Crisp on the Definition of Presentism}

In papers that appear shortly before Meyer's, Crisp (2004a, b) considers the same problem, claiming to come to a solution on behalf of the presentist. Getting clear on why Crisp's attempt at a solution fails will be instructive; it will help us get to the heart of the problem.

Crisp suggests that the presentist should endorse the following analysis of presentism.

$\left(\operatorname{Pr}_{\mathrm{b}}{ }^{\prime \prime}\right)$ For every $\mathrm{x}, \mathrm{x}$ is a present thing

The objector will, as Crisp notes, claim that $\left(\operatorname{Pr}_{\mathrm{b}}{ }^{\prime \prime}\right)$ is false. The objector to $\left(\operatorname{Pr}_{\mathrm{b}}{ }^{\prime \prime}\right)$ will claim that entities such as the Roman Empire provide us with a counterexample: the Roman Empire is an $\mathrm{x}$, but is not a present thing. (This is reminiscent of Meyer's response to the claim that we might try to define presentism using 'exists temporally'.).

This objection errs, Crisp thinks. We need to distinguish between the de dicto assertion that

$\left(\mathrm{RE}_{1}\right)$ WAS(for some $\mathrm{x}, \mathrm{x}$ is the Roman Empire and $\mathrm{x}$ will not exist in $\mathrm{t}_{\alpha}$ ) 
where " $\mathrm{t}_{\alpha}$ " names the present moment, and the de re assertion that

$\left(\mathrm{RE}_{2}\right)$ For some $\mathrm{x}, \mathrm{x}$ was the Roman Empire and $\mathrm{x}$ is no longer present

Everyone, Crisp thinks, will agree with $\left(\mathrm{RE}_{1}\right)$. It is a trivial truth much like $\mathrm{P} 1 *$. However, not everyone need agree with $\left(\mathrm{RE}_{2}\right)$. In particular, the presentist will not agree with $\left(\mathrm{RE}_{2}\right)$. The presentist will not agree that " $\mathrm{x}$ is the Roman Empire and $\mathrm{x}$ is no longer present" is satisfied by some res in $\mathrm{D}_{t}$ ' (Crisp 2004a: 18). Nor, Crisp claims, is this a problem. It is no Moorean truth that the domain of temporal things is populated with something that is both non-present and identical with the Roman Empire. This might leave us thinking that we have a response to Meyer.

Crisp's definition is, however, prone to Meyer's objection. It will help us to have a more formal understanding of $\mathrm{RE}_{1}$ and $\mathrm{RE}_{2}$ in what follows. Thus,

$\left(\mathrm{RE}_{1}{ }^{*}\right)$ WAS $\exists \mathrm{x}\left(\mathrm{x}\right.$ is the Roman Empire, \& $\sim$ WILL $\exists \mathrm{x}$ at $\left.t_{\alpha}\right)$

$\left(\mathrm{RE}_{2}{ }^{*}\right) \exists \mathrm{x}(\mathrm{x}$ was the Roman Empire and $\sim$ PRES $\mathrm{x})$

Crisp thinks that $\mathrm{RE}_{2}$ [and, thus, $\left(\mathrm{RE}_{2} *\right)$ ] will be rejected by the presentist. But to determine whether or not that's plausible, we must, following Meyer's argument, pick one of the two readings of 'exist' available to us, as the verb is expressed by the quantifiers in the above: either present-tensed to mean 'exist now', ' $\exists_{\mathrm{n}}$ '; or the sense of 'exist' that means 'temporally existed', ' $\exists_{\mathrm{t}}$ '.

That gives us two ways in which we can disambiguate $\mathrm{RE}_{2} *$.

$\left(\mathrm{RE}_{2} * \mathrm{a}\right): \exists_{\mathrm{n}}$ (x was the Roman Empire and $\sim$ PRES $\mathrm{x}$ )

$\left(\mathrm{RE}_{2}{ }^{*} \mathrm{~b}\right): \exists_{\mathrm{t}}(\mathrm{x}$ was the Roman Empire and $\sim$ PRES $\mathrm{x})$

It's easy to see that we will face a problem. Whilst the presentist denies $\left(\mathrm{RE}_{2} * \mathrm{a}\right)$, so does the eternalist. No-one thinks that $\left(\mathrm{RE}_{2} *\right.$ a) is true because endorsing it requires us to endorse a contradiction; we would be claiming that there now exists an $\mathrm{x}$ that was the Roman Empire but that it is not present. How can something now exist and not be present?

To differentiate presentism from eternalism the presentist must deny $\left(\mathrm{RE}_{2} * \mathrm{~b}\right)$. But the presentist cannot sensibly deny $\left(\mathrm{RE}_{2} * \mathrm{~b}\right) .{ }^{\prime} \exists_{\mathrm{t}} \mathrm{x}(\mathrm{x})$ ' is true iff $\mathrm{x}$ either has existed, does exist or will exist. Since the Roman Empire has existed, but is not present, it is therefore true to say that ' $\exists_{\mathrm{t}}$ ( $\mathrm{x}$ WAS the Roman Empire and $\sim$ PRES

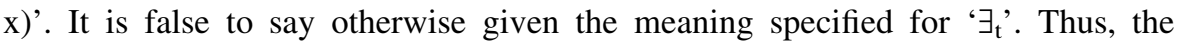
presentist must endorse $\left(\mathrm{RE}_{2} * \mathrm{~b}\right)$. We are faced with the problem once more.

Before we move on it is worth noting a potential concern with the line of argument I took above. I specified that 'For some x' in Crisp's original statement of presentism was to be replaced by the existential quantifier, and then specified that the quantifiers expressed the English verb 'exists'. That might strike some as odd since the verb 'exists' appears no-where in Crisp's original statement of presentism. Any bafflement can be removed, I assume, simply by keeping in mind that 'For some $\mathrm{x}$ ', is but a short-hand way of expressing the claim 'For some existing x...', or 'there are some things, the xs, such that....'. (In the latter case, 'there are' seems to be expressing the claim 'there exist some'). Were it not such a short-hand then it would be true that 'for some $\mathrm{x}, \mathrm{x}$ is a winged horse', even though there does not 
exist a winged horse - and most are inclined to reject such claims. Once we allow the verb 'exists' into the definition of presentism, via the quantifier, then the problem rears its head once more, as I have shown in the arguments above. ${ }^{2}$

I think that it's easy to point to the inference that Meyer makes to which the presentist should object. It is less easy to see what to do about it. Speaking of Caesar, Meyer (2005: 214) remarks:

if he did exist then he does exist at some past time, and therefore does exist temporally

Now no presentist will want to concede that this is true. Nor will they want to concede that the inference from 'WAS $\exists_{\mathrm{n}} \mathrm{x}\left(\mathrm{x}^{\prime}\right)$ to $\exists_{\mathrm{t}} \mathrm{x}(\mathrm{x})$ ' is valid (not, at least, if ' $\exists_{\mathrm{t}} \mathrm{x}$ ' is our most inclusive reading of the existential quantifier). So the presentist must think that the inference is faulty. But given the meanings of the terms involved, 'it was the case that, there now exists an $x$ ', entails that 'there 'exists temporally' an x'. It is therefore hard to see how we should proceed.

At this point it's worth pausing a moment in order to consider a rather different view of the role played by the existential quantifier and the role played by the verb 'exists' more generally. I have been proceeding here, in accordance with a mainstream view according to which the existential quantifier says little more than 'there is some thing, such that....'. This kind of view is one that we may describe as broadly Quinean. The role of the verb 'exists' is to tell us that there is some object to which we may then attribute properties. But this is not the only available view of existence. Though it is certainly not mainstream, there is another view of existence, due to Colin McGinn (2000), according to which there is a legitimate distinction between existence and being, and although everything that exists has being, the converse is not true; there are objects that have being that do not exist. If we took this view of existence then we might say that the only objects that have the property of existence are those that have the property of presence. Thus, although there might be objects other than those that are present, they do not have the property of existing.

This might help us solve the problem-raised by Meyer-for the following reason. On the McGinn inspired view, 'exists' will be a primitive predicate denoting a primitive property of objects. In that case, the claim that 'only present objects exist' amounts to the view that: 'only objects that have the property of presence have the property of existing'.

However, the definition just given still seems to fall foul of the objection-if inspected in sufficient detail. The claim that 'only objects that have the property of presence have the property of existence' must be read in one of the following four ways:

\footnotetext{
2 There is another move that might be made, which is to stipulate that there is a tenseless reading of 'exists'. This possibility is explored, and persuasively rejected, in Stoneham (2009), so I will not pursue it further. Nonetheless, some presentists still assume that such a reading is available and then use that tenseless reading of the quantifier to generate a definition of presentism. A good (recent) example of this is Rasmussen (2012: 271), who notes some of the concerns raised in the wider literature, and then remarks: 'I won't enter into that debate here, however, because in seeking to develop a tenseless version of presentism, I will assume (for the sake of argument) that tenseless quantification is intelligible.' Stoneham's point, of course, is that this assumption is not one that we can, or should, make.
} 
[McG1] Only objects that [now] have the property of presence [now] have the property of existence

If we assume McGinn's account of existence, then this is trivially true and the eternalist should agree. Only things that are now present now have the property of existing; non-present objects do not now have any properties

[McG2] Only objects that [now] have the property of presence have had, now have, or will have the property of existence

This is false. On McGinn's view, objects have being even if they lack existence. Thus, there are such objects as the Roman Empire-even if they don't exist. That being the case, there are objects - such as the Roman Empire-that do not have the property of presence, but that have had the property of existence.

[McG3] Only objects that have had, have, or will have, the property of presence [now] have the property of existence

Once more, this will not succeed. Imagine a growing block world, according to which the past and present exist. Imagine a version of such a world at which every object that has existed persists into the present. It is true to say of such a world that only objects that have existed now have the property of presence.

[McG4] Only objects that have had, have, or will have, the property of presence, have had, have, or will have, the property of existence.

This seems trivially true and, once again, could be agreed to by the growing block theorist. Objects that were present, had the property of existence-this much is certainly true and should be agreed to by presentist and eternalist alike. That being the case, $[\mathrm{McG} 4]$ cannot be a definition of presentism. Tentatively, then, I conclude that direct appeal to a McGinn style account of existence does us no good here.

\subsection{Stoneham on the Definition of Presentism}

One way in which we might try to make an advance is due to Stoneham (2009). Stoneham uses 'exists' in the present tense. Stoneham claims that the way in which to understand the distinction between presentism and eternalism lies in an understanding of the truth-maker principle. I take the truth-maker principle to be the following:

TM: Necessarily, if $<\mathrm{p}>$ is true, then there is some entity in virtue of which it is true. (cf. Rodriguez-Preyera (2005: 18))

Tentative motivations for the view are easy enough to find. For instance,

My hope is that philosophers of realist inclinations will be immediately attracted to the idea that a truth, any truth, should depend for its truth on something 'outside' it, in virtue of which it is true. (Armstrong (2004: 7)).

Thus, consider the following two putative truth-maker principles. 
(TM1) If $<\mathrm{p}>$ is true, then there now exists some object $\mathrm{x}$, such that $<\mathrm{x}$ exists $>$ strictly implies $<\mathrm{p}>$,

and:

(TM4) If $<\mathrm{p}>$ is true, then either there is, was or will be some object $\mathrm{x}$, such that $<\mathrm{x}$ exists $>$ strictly implies $<\mathrm{p}>$. $^{3}$

Stoneham (2009) thinks that consideration of (TM1) and (TM4) permits us to articulate a difference between the presentist position and the eternalist position. The presentist, but not the eternalist, will endorse (TM1); the eternalist, but not the presentist, will endorse (TM4). Thus it would appear that we have a solution to the problem of how to describe presentism: presentism unlike eternalism, requires a commitment to (TM1).

However, I do not think that the route Stoneham suggests is one that we should take. The source of the problem concerns Stoneham's suggestion that we rely on truth-maker maximalism: the view that every true-proposition requires a truthmaker. Such an extreme position seems hard to defend. It seems far more natural to suppose that truths like 'there are no hobbits' are true, not because some entity exists that makes them true, but because there is no entity that exists that makes them false. 4

In response to this kind of intuitive concern we might try to water down Stoneham's account of the difference between presentism and eternalism utilizing a weakened version of the truth-maker principle. The problem case, described above, is an instance of a negative existential; it is a claim that a particular object does not exist (hobbits, in that case). To weaken the truth-maker principle appropriately, we might then allow that not all truths have truth-makers and take the line that only those propositions about what exists require truth-makers. ${ }^{5}$

Let us then deploy this insight and modify (TM1)*.

(TM1)* If $<\mathrm{p}>$ is a true proposition about what exists, then there now exists some object $\mathrm{x}$, such that $<\mathrm{x}$ exists $>$ strictly implies $<\mathrm{p}>$

Immediately, however, the problems become apparent. The italicized portion of (TM1)* explicitly deploys the verb 'exists'. So to understand (TM1)* we must first decide upon the tense of 'exists' as it appears in the italicized portion of (TM1)*. 6 Drawing on the discussion from Sect. 2, there are two versions available:

(TM1a)* If $<\mathrm{p}>$ is a true proposition about what exists now, then there now exists some object $\mathrm{x}$, such that $<\mathrm{x}$ exists $>$ strictly implies $<\mathrm{p}>$

\footnotetext{
3 The numbering is Stoneham's.

${ }^{4}$ For arguments in this vein, see Lewis (1992), Merricks (2007), Mumford (2005, 2007) and Simons (2005, 2008).

5 For more detailed accounts of how such a strategy might work, see Tallant (2009a, 2010).

${ }^{6}$ Since this thesis is supposed to be presentist-friendly, I assume that the 'exists' that appears in the proposition $<\mathrm{x}$ exists $>$ is to be read as present-tensed.
} 
(TM1b)* If $<\mathrm{p}>$ is a true proposition about what has existed, does exist, or will exist, then there now exists some object $\mathrm{x}$, such that $<\mathrm{x}$ exists $>$ strictly implies $<\mathrm{p}>$

No-one should deny (TM1a)*. If $<\mathrm{p}>$ is a true proposition about $\mathrm{x}$, where $\mathrm{x}$ exists now, then the truth of $<\mathrm{x}$ exists $>$ strictly implies $<\mathrm{p}>$.

That would look to leave us with (TM1b)*. (TM1b)* requires us, as presentists, to maintain that a true proposition about the past is true because there now exists some $x$, such that the truth of $<x$ exists now $>$ strictly implies the truth of a proposition, $\langle\mathrm{p}>$, that is about the past. The best way to illustrate this kind of maneuver is by recourse to an example. Let us borrow Bigelow's (1996) Lucretianism, according to which the truth of past-tense propositions are grounded in the existence of presently existing properties, instantiated by the world, of the form having contained so-and-so. Thus, the reason that the proposition $<$ there were dinosaurs $>$ is true is that there now exists a Lucretian property has contained dinosaurs. This property is instantiated by the world, such that the world has contained dinosaurs. So, there now exists some object, $\mathrm{O}$,- the world instantiating the property having contained dinosaurs - such that $<\mathrm{O}$ exists $>$ strictly implies $<$ there were dinosaurs $>$.

As this example illustrates, the presentist can endorse (TM1b)*. But I do not think that the presentist should endorse (TM1b)*. The intuition that motivated the restriction to the truth-maker principle was the intuition that true propositions about what does not exist do not require truth-makers. The presentist claims that propositions about the past are propositions about what does not exist. Thus, the presentist should deny that there are truth-makers for true propositions about what has existed and what will exist. Thus, the presentist should deny (TM1b)*. ${ }^{7}$

There is another reason for the presentist to deny (TM1b)*. Sanson and Caplan (2010) invite us to consider the true proposition, A: Arnold was pale. They deny that presentists should posit presently existing truth-makers, such as Lucretian properties, for true propositions like A. The route Sanson and Caplan take to showing that the presentist should agree that there are no truth-makers for propositions like $\mathrm{A}$ is to demonstrate that, intuitively, propositions about the past depend for their truth, not upon what exists, but upon what did exist. In their own words: 'we argued that a proper explanation of the truth of $A$ points, not to a property that Arnold now has, but rather to a property that he once had' (2010: 30). Here, in more detail, is their reasoning:

As we have insisted, we must accept that the explanation of the truth of $\mathrm{A}$ points to properties Arnold once had. This does not commit us to objectionably hypothetical entities: neither Arnold nor the property being pale is objectionably hypothetical. But it does commit us to a kind of irreducibly hypothetical explanation, an explanation that "points beyond" what there is and what properties and relations things instantiate. (2010: 37)

They go on,

\footnotetext{
7 This is a shortened version of the argument offered by Tallant (2009b: sections 4 and 5). See, also, Merricks (2007: 133-144) and Kierland and Monton (2007).
} 
A is true because Arnold once instantiated the property being pale. This explanation does not point to what there is or how things are. It "points beyond" reality, to describe how things once were and, in particular, to describe a property Arnold once instantiated. (2010: 38)

These two arguments together strike me as a convincing riposte to the claim that the presentist should endorse (TM1b)*. Because of these sorts of consideration, I think that the presentist should deny (TM1b)*.

But that might not matter. We still have (TM4) to work with. Perhaps we can simply stipulate that what is key to describing the difference between presentism and eternalism is that eternalists and not presentsits endorse (TM4). That would be enough to get us a difference between the two views and so might give us something that will allow us to define presentism.

As with (TM1), we require a weakened version of the principle to avoid endorsing truth-maker maximalism. That gives us

$(\mathrm{TM} 4)^{*}$ If $<\mathrm{p}>$ is a true proposition about what exists, then either there is, was or will be some object $\mathrm{x}$, such that $<\mathrm{x}$ exists $>$ strictly implies $<\mathrm{p}>$

Within (TM4)* the verb 'exists' appears twice. With two readings of the verb 'exists' (exists and exists $_{\mathrm{t}}$ ) that gives us four potential readings of (TM4)*.

(TM4a) If $<\mathrm{p}>$ is a true proposition about what exists now, then either there is, was or will be some object $\mathrm{x}$, such that $<\mathrm{x}$ exists now $>$ strictly implies $<\mathrm{p}>$

No-one should deny (TM4a). If $<\mathrm{p}>$ is a true proposition about what exists now, then, intuitively, $<\mathrm{p}>$ requires a truth-maker that exists now.

(TM4b) If $<\mathrm{p}>$ is a true proposition about what existed, exists now, or will exist, then either there is, was or will be some object $\mathrm{x}$, such that $<\mathrm{x}$ has existed, exists now, or will exist $>$ strictly implies $<\mathrm{p}>$

Both presentist and eternalist should endorse (TM4b). Suppose that $<\mathrm{p}>$ is the proposition $<$ there were dinosaurs $>$. It's true that there was some $\mathrm{x}$ such that the truth of $<$ dinosaurs have existed $>$ strictly implies $<$ there were dinosaurs $>$. In this case, $\mathrm{x}$ is simply a dinosaur.

(TM4c) If $<\mathrm{p}>$ is a true proposition about what exists now, then either there is, was or will be some object $\mathrm{x}$, such that $<\mathrm{x}$ existed, exists or will exist $>$ strictly implies $<\mathrm{p}>$

Again, both presentist and eternalist should endorse (TM4c): it says nothing more than that, if $<\mathrm{p}>$ is a proposition about the present, then $<\mathrm{p}>$ will require a presently existing truth-maker or an object that did exist that makes it true or an object that will exist that will make it true. This disjunction is itself true because a proposition that is about what presently exists requires a presently existing truth-maker.

Finally,

(TM4d) If $<\mathrm{p}>$ is a true proposition about what existed, exists now, or will exist, then either there is, was or will be some object $\mathrm{x}$, such that $<\mathrm{x}$ exists now $>$ strictly implies $<\mathrm{p}>$ 
The eternalist should not endorse (TM4d). Consider the proposition $<$ there were dinosaurs $>$. The eternalist should not agree that there existed, or now exists, or will exist, some object $\mathrm{x}$, such that $<\mathrm{x}$ exists now $>$ strictly implies that $<$ there were dinosaurs $>$. Rather, the eternalist should state that: there was some object $x$ such that $<$ there existed $\mathrm{x}>$ strictly implies $<$ there were dinosaurs $>$.

As they could accept (TM1b)*, the presentist could accept (TM4d) - and that might then give us a difference between presentism and eternalism and so a means with which to define presentism. But, for the same reasons I suggested that they should reject (TM1b)*, I think that the presentist should reject (TM4d). Once more, (TM4d) requires that the present existence of some object, $x$, be such that $<x$ exists $>$ strictly implies a past-tense proposition. As before, a Lucretian property is a suitable stalking-horse. And, as before, we have two reasons to reject this approach. The first reason to reject this kind of approach is that what motivates our restriction to the truth-maker principle in the first place is that truths about what does not exist, do not require truth-makers. Since this is a case where a proposition, $<p>$ is about what does not exist $-<\mathrm{p}>$ is a proposition about the past-we should not be looking for truth-makers for $\langle\mathrm{p}\rangle$. The second reason to reject this kind of approach is that, following Sanson and Caplan (2010), presently existing truth-makers look to be poor candidates for the role of explaining why past-tense propositions are true. Because of this, I do not think that the presentist should endorse (TM4d). We are once again left without a means of defining presentism.

\subsection{Crisp's Other Account}

Crisp (2005a, b) offers a second definition of presentism. He describes presentism as the view that:

it's always the case that, quantifying unrestrictedly, nothing is at any temporal distance from anything.

Crisp goes on:

I leave undefined the notion of temporal distance in play here, though the intuitive idea should be clear enough. If our most inclusive domain of quantification includes past as well as present entities, it presumably includes Lincoln's assassination. Suppose so. Then the temporal distance between his assassination and the present is a bit less than 140 years

Crisp's definition of presentism is not one that I find palatable for the 'intuitive idea' of temporal distance to which Crisp appeals is not clear; nor is it intuitive.

I don't claim to demonstrate that his definition must fail. My arguments here merely show that, at least as matters stands, the concept of temporal distance will not help us in our quest for a definition of presentism. To bring this out, let us carefully consider what exactly 'temporal distance' might consist in, and how this is to help us to understand the claim that nothing exists at any temporal distance from anything. 
Consider,

$\mathrm{TD}_{1}$ : ' $\mathrm{x}$ is at a temporal distance from $\mathrm{y}$ ' is true iff there's "temporal distance", analogous to spatial distance, such that any entities, $x$ and $y$, are separated by temporal distance

$\mathrm{TD}_{1}$ is not quite right. Clearly there is some analogy between being 'earlier than' and being 'to the North of'. No matter where one goes in space, if $\mathrm{x}$ is ever North of $\mathrm{y}$, then $\mathrm{x}$ is always North of $\mathrm{y}$. Nottingham is North of London whether I am in Cardiff, Aberdeen, or any other location. Likewise, no matter what the time, if the Battle of Hastings is ever earlier than the First World War, then the Battle of Hastings is always earlier than the First World War. If there's some analogy between being 'earlier than' and being (say) 'to the North of', then $\mathrm{TD}_{1}$ fails when we try to define presentism, for when we say that 'nothing is at any Temporal Distance $_{1}$ from anything', then we say that 'nothing is earlier or later than anything else'. That's false. The Battle of Hastings is earlier than the First World War. The First World War is earlier than the Second World War.

Of course, the problem with Temporal Distance ${ }_{1}$ is that it includes only a very loose requirement on there being 'some analogy' between spatial and temporal distance. What we need to do to improve matters is to make this condition more precise. Thus

$\mathrm{TD}_{2}$ : ' $\mathrm{x}$ is at a temporal distance from $\mathrm{y}$ ' is true iff $\mathrm{x}$ stands in a fixed and permanent temporal relation to $\mathrm{y}$.

The first worry that I have with this proposal is that, as we have already seen, most presentists want to say that (in the sense that some events may be accurately described as being 'earlier than' or 'later than' others) there are fixed and permanent temporal relations. It just so happens, however, that these relations are to be further analyzed in terms of tensed notions [or ersatz relations, Crisp (2005b)]. ${ }^{8}$ Presentists certainly should not want to deny that, for instance, 'the Battle of Hastings is earlier than the First World War'.

A further worry with $\mathrm{TD}_{2}$ is that the presentist might be inclined to the view that all existing entities are simultaneous with one another. Simultaneity is a fixed and permanent temporal relation. If $\mathrm{x}$ is simultaneous with $\mathrm{y}$ then $\mathrm{x}$ is always simultaneous with $y$. Thus, there could be fixed and permanent temporal relations at a presentist world where $\mathrm{TD}_{2}$ would rule that out.

$\mathrm{TD}_{3}$ : ' $\mathrm{x}$ is at a temporal distance from $\mathrm{y}$ ' is true iff $\mathrm{x}$ is earlier than $\mathrm{y}$ or later than $y$, and the only sense in which it's true to say that ' $x$ is earlier than $y$ ' is via some reduction of the earlier than/later than relation.

$\mathrm{TD}_{3}$ has the benefit of ruling out $\mathrm{x}$ 's being simultaneous with $\mathrm{y}$ as $\mathrm{x}$ 's being at a temporal distance from y. It also seems as if it gets at what we want to say about temporal distance: there can only be temporal distance if there is an unanalyzed relation of 'earlier than' and 'later than'.

\footnotetext{
${ }^{8}$ See Markosian (1993: sect 2, esp. fn 12) for discussion of how presentists try to preserve temporal relations.
} 
Perhaps this is the sense of temporal distance that Crisp has in mind. But, if it is, then we have a genuine problem on our hands for this still doesn't suffice to generate an account of temporal distance that will be of use to the presentist. There are metaphysics according to which nothing exists at any Temporal Distance ${ }_{3}$ from anything else, but that are not presentist metaphysics. The growing block theorist (who believes in the reality of the past and present) may concede that "earlier than" is to be reductively analyzed using tensed notions but believes that there are no objects that exist at a Temporal Distance ${ }_{3}$ from one another. ${ }^{9}$ So, a growing block world could be one at which nothing exists at a Temporal Distance ${ }_{3}$ from anything else; but a growing block world would not be a presentist world.

I'm now out of ideas as to how to understand what it is that we're supposed to be saying when we deny that there are entities that exist at a 'temporal distance' from one another and how this is supposed to help define presentism. I don't want to say, here, that there's no satisfactory notion of temporal distance that can be elucidated in support of the presentist view. My claim in this passage is more meager. If the analysis of presentism is to be completed via an understanding of temporal distance, then we must have a suitable definition of temporal distance. At the moment, we lack an account of what temporal distance is supposed to consist in, and how that can be deployed in an adequate definition of presentism.

\subsection{Sider on Temporal Quantifiers}

Sider (2006) argues that the disagreement between presentist and eternalist is genuine. Does material therein suggest a way in which we can characterize presentism in such a way as to avoid Meyer's complaint? It does not.

Sider's concern is to demonstrate that there is a legitimate disagreement between presentist and eternalist. Sider (2006: 77) diagnoses the source of scepticism to the contrary as follows. Presentists and eternalists agree on the truth-values of many natural language tensed claims, for instance

(2) Dinosaurs once existed ${ }^{10}$

This is, according to Sider, what breeds scepticism about temporal ontology. After all, if we all agree that (2) is true, then what are we really arguing about when we deny/assert that there exist past and future objects? Sider then goes on to point out that this putatively problematic sentence can be given both an eternalist treatment and a presentist treatment. The eternalist treatment:

(2E) There exist dinosaurs, located temporally before us.

$\exists x(D x \& B x u)$

The presentist treatment:

\footnotetext{
9 For instance, Button (2006, 2007). Lowe (1998) also offers a 'tensed' metaphysic and will, it seems likely, offer an analysis of 'earlier than'. At a world at which Lowe's metaphysic is correct, nothing will exist at any Temporal Distance from anything else, for there is no unanalyzed 'earlier than'/later than' relation; but such a world is not presentist.

${ }^{10}$ I follow Sider's numbering.
} 
(2P) It was the case that: there exist dinosaurs. ${ }^{11}$

WAS $\exists \mathrm{xDx}$

The crucial difference between these two regimentations, according to Sider, is that whereas (2E) entails $\exists x[\mathrm{Dx}],(2 \mathrm{P})$ does not. Because presentists think that $(2 \mathrm{E})$ is false, they do not think that there are dinosaurs $\exists x[D x]$. Thus, we have clear water between the presentist and eternalist. Although we may not be able to give a pithy slogan to capture the distinction between the two views, we can at least specify the difference between the two views as consisting in their endorsing different entailments.

However, as Sider (2006: 79) acknowledges, there is scope for the sceptic to reply.

The sceptic must reply that presentists and eternalists do not mean the same thing by (2E) after all. Presentists reject that sentence, according to the sceptic, only because they do not realize that it means the same thing as one of the sentences they accept. A likely candidate is $(2 \mathrm{P})$. (2P), the sceptic could claim, is just the presentist's way of saying what the eternalist means by (2E). That is, the sceptic could claim that for some translation function, $\mathrm{f}, \mathrm{f}((2 \mathrm{E}))=(2 \mathrm{P})$.

In response, Sider (2006: 79) introduces the notion of a 'genuinely quantified claim'. At a first pass this amounts to the idea that an expression is genuinely quantified iff its main syntactic connective expresses the notion of existence-as is the case in 'there are electrons'. In his own words:

The crux. I have said that $(2 \mathrm{P})$ is not genuinely quantified and so does not translate (2E). As I see it, the sceptic must reply that $(2 \mathrm{P})$ is genuinely quantified. ' $\mathrm{P} \exists \mathrm{x}$ ' is just the presentist's way of writing the eternalist's existential quantifier over past entities. The sceptic must admit that (2E) and (2P) differ syntactically, but she will say that this difference is superficial, the result of an arbitrary choice to express the same claim in one vocabulary rather than another. Other than in this superficial respect, the sceptic will claim, (2E) and (2P) do not differ. They have the same inferential role, the sceptic will claim. Presentists use (2P) in exactly the same situations in which eternalists use (2E) (when not in the philosophy room, anyway).

The sceptic's challenge may be put thus: why doesn't the expression ' $\mathrm{P} \exists \mathrm{x}$ ' count as 'a genuine quantifier'? ${ }^{12}$

Sider then seeks to respond to this challenge by demonstrating that 'WAS $\exists$ ' doesn't behave, inferentially, like the eternalist's quantifier. Again, I shall quote at length:

\footnotetext{
${ }^{11}$ Note: in Sider (2006) the symbol that I'm notating as 'WAS' is presented as 'P'. In the interests of consistency within this paper, I've replaced instances of 'P' with 'WAS' wherever they fall outside quotation.

${ }^{12}$ As a reminder to the reader, Sider's 'P' has the same content as the symbol 'WAS' that we have been using elsewhere.
} 
For clarity's sake, let us reserve the quantifiers $\exists$ and $\forall$ for the presentist, and introduce distinct notation for the eternalist. Let $\Sigma \mathrm{P}$ be the eternalist's unrestricted existential quantifier over past objects. And let us express restricted quantification over past things thus:

$(\Sigma \mathrm{P} \mathrm{x}: \mathrm{Kx}) \varphi$ "Some past $\mathrm{K}$ is $\varphi$ "

One feature of the inferential role of restricted existential quantifiers is that pairs of them commute:

$(\Sigma \mathrm{Px}: \mathrm{Kx})(\Sigma \mathrm{Py}: \mathrm{Ly}) \varphi \sim=(\Sigma \mathrm{P}$ y : Ly $)(\Sigma \mathrm{P} \mathrm{x}: \mathrm{Kx}) \varphi(' \sim=$ stands for logical equivalence). Now, if $\mathrm{P} \exists \mathrm{x}$ is the presentist's translation of $\Sigma \mathrm{Px}$, then presumably the translation of $(\Sigma \mathrm{P} \mathrm{x}: \mathrm{Kx})$ is $\mathrm{P}(\exists \mathrm{x}: \mathrm{Kx})$. But the presentist translation of the above equivalence does not hold:

$\mathrm{P}(\exists \mathrm{x}: \mathrm{Kx}) \mathrm{P}(\exists \mathrm{y}: \mathrm{Ly}) \varphi \mathrm{P}(\exists \mathrm{y}: \mathrm{Ly}) \mathrm{P}(\exists \mathrm{x}: \mathrm{Kx}) \varphi(2006: 85)$

The natural thought, then, is that if these quantified claims are not equivalent, then there is a genuine, logical difference between presentism and eternalism.

But Sider's argument fails; at least, it will not give us a satisfactory definition of presentism. Sider's key claim, noted above, is that the presentist denies that $\mathrm{P} \exists \mathrm{xDx}$ entails $\exists x D x$. Let us call this principle DENIAL.

DENIAL: It is not the case that, $\mathrm{P} \exists \mathrm{x}[\mathrm{Dx}]$ entails $\exists \mathrm{x}[\mathrm{Dx}]$

The presentist is supposed to endorse DENIAL. But, I claim, they cannot. Once again we find ourselves pressed to answer the question 'what tense of 'exist' does ' $\exists$ ' express?' Suppose that ' $\exists$ ' expresses the present-tensed sense of 'exists'. In that case, DENIAL amounts to:

DENIAL(a): It's not the case that WAS $\exists_{\mathrm{n}} \mathrm{x}$ [Dx] entails $\exists_{\mathrm{n}} \mathrm{x}$ [Dx]

This principle is obviously false. Everyone (I assume) agrees that we should reject the claim that 'it was the case that, there now exist dinosaurs' entails that 'there now exist dinosaurs'. The presentist cannot endorse this DENIAL(a).

In contrast, if we took ' $\exists$ ' to express the 'temporal' sense of 'exists', then that would give us:

DENIAL(b): It's not the case that, WAS $\exists_{\mathrm{t}} \mathrm{x}[\mathrm{Dx}]$ entails that $\exists_{\mathrm{t}} \mathrm{x}[\mathrm{Dx}]$

But DENIAL(b) is false. ' $\exists_{\mathrm{t}} \mathrm{x}[\mathrm{Dx}]$ ' is translated as 'there have been, are now, or will be dinosaurs'. This is entailed by WAS $\exists_{\mathrm{t}} \mathrm{x}[\mathrm{Dx}]$, which is translated as 'it was the case that, there have been, are now, or will be dinsoaurs'. Sider's recourse to talk of genuinely quantified claims fails to be of use to us in our efforts to define presentism.

To conclude this opening section of the paper: I don't take the arguments here to show conclusively that there is no way of defending CP. Maybe there is. My claim is simply that the views surveyed, due to Crisp (2004a, b), Stoneham (2009), the later Crisp (2005a) and Sider (2006), are treated, in the wider literature, as ways in which presentism can be defined. Indeed, Crisp's (2004a, b) account is echoed by Markosian (2004) and something like it is taken to be the conventional and mainstream way of 
describing presentism - thus my dubbing it CP. Because of this, it is important to see that the view fails if it is described in this way. It is also important to note that Meyer is not alone in thinking that this type of concern will cause problems for the presentist. ${ }^{13}$ Because of these issues, it is important to see if there is another way of defining presentism that avoids these problems.

\section{Existence and Presentism}

The way in which I think we should define presentism takes its cue from Merricks (2007: 123-125).

Presentists and eternalists alike say that those things that exist at the present time really do exist and, moreover, that properties had at the present time really are had. Thus one might think, whilst presentism and eternalism part ways with respect to other times, they agree about the nature of the present time, and, relatedly, agree about what it is to exist (and have properties) at the present time. But they do not agree about these things. Indeed, their differences with respect to the nature of, and existence at, the present time are as important as their differences with respect to the past and future. (2007: 123)

According to Merricks, the distinction between presentism and eternalism must include a difference in how we understand existence.

'consider a view that starts off with the eternalist's picture of time and existence at a time, and then 'shaves off' the past and future, leaving only a thin (instantaneous?) slice called 'the present'. This view agrees with eternalism that existing at a time-any time, past, present, or future-is like being located at a place. But, unlike eternalism, this view says that while objects exist at the present time, they exist at no other times, since there are no other times at which to be located. (2007: 124)

Merricks does not think that this is an appropriate way in which to describe presentism.

I can see why some might think this view is presentism. They think that this view is presentism because they (wrongly) ascribe to presentists the eternalsit's claim that to exist at a time is to be located at some super-thin slice of being. But presentists should no more accept this than the nonLewisian should accept that to possible exist is to be located in some universe. (2007: 124)

What, according to Merricks, should they say?

\footnotetext{
${ }^{13}$ For instance, Lombard (2010). It's also worth drawing to the attention of the reader the fact that Stoneham (2009) argues extensively and persuasively that Crisp-(2004a, b)-style definitions of presentism fail for reasons similar to those given by Meyer. I don't repeat Stoneham's arguments, but I do recommend them to the reader.
} 
Since they do not believe in a region called the 'present time', presentists cannot reduce existing at the present time to being located at that region. I think presentists should, instead, say that existing at the present time just is existing. (2007: 125)

I think that Merricks' proposal moves in the right direction. It ties presentism to a claim about the nature of existence. It seems right that presentism ought to be understood, not merely as a thesis concerning the number of times that exist, but also as thesis with a commitment to the nature of those times.

However, the core thesis advanced by Merricks, that 'existing at the present time just is existing' is not one that I find perspicuous - at least, not as it stands. For the presentist, 'existing at the present time' is simply to be understood as 'existing'. For the eternalist, 'existing at the present time' is to be understood as 'existing at some time-slice simultaneous with this sentence'-or something similar. Here is the problem: the sentence, 'existing at the present time just is existing' contains the copula, 'is'. The two different readings of the tense of this 'is' give rise to two different ways in which we might understand the definition of presentism.

(M1)Existing at the present time just is now existing

(M2)Existing at the present time just has been, is, and will be, existing

(M1) is trivially true. (M2) is false. Existing at the present time (e.g. 2012) may now be existing; but it is not the case that it has been existing. There are many entities that 'have been existing', that are not existing at the present time: the Battle of Hastings, Elvis Presley, dinosaurs, etc. Since these entities have been existing, but do not exist at the present time, so having been existing cannot be 'existing at the present time'.

I have similar concerns about the definition of presentism offered to us by Zimmerman (1996). Like Merricks, Zimmerman seeks to define presentism by drawing an intimate connection between being present and existing. Zimmerman offers the following as his preferred definition of presentism:

'to be present just is to be real or to exist' (1996: 117)

I think that, in order to avoid Meinongian concerns about existing entities that are unreal, we ought to disregard the disjunction and treat this as:

To be present just is to exist

There are two readings of this:

D1) To be present just is to exist-now

D2) To be present just is to have existed, to exist-now, and to be going to exist

For familiar reasons, D1 is trivial. D2 is obviously false; after all, to be present is not to have existed. Thus the proposals offered by Zimmerman and Merricks will not serve to properly define presentism. ${ }^{14}$

\footnotetext{
14 Might we treat the 'is' here as tenseless? If we could, then the problems might disappear. For reasons to think that this route is not available, see Stoneham (2009: 205-210).
} 


\subsection{Existence Presentism Stated}

The proposals from Merricks and Zimmerman have something in common: both posit a close connection between being present and existence. I suggest, then, that the best way in which to make sense of this is to identify being present with existing.

However, talk of 'being' present, carries with it a slight awkwardness given the natural tendency to draw a close connection between existence and being; it looks to leave the same notion on both sides of the analysis.

In addition, I will have cause to talk of 'presence' being a name-of a property, category, etc. Talk of 'being present' is suggestive of an activity rather than a name. Thus, in what follows and in order to keep in mind that I am trying to talk about a thing, I will talk instead of 'presence' (rather than 'being present') and existence.

Thus, EP amounts to:

\section{EP: Presence is existence ${ }^{15}$}

Some remarks of a clarificatory nature are in order. To begin, notice that both 'presence' and 'existence' are nouns (and in some of what follows I will treat them as the name of properties). The copula is tensed. EP expresses a tensed sentence. To bring this out, we might say 'Presence is now the very same thing as existence'. That this sentence is explicitly present-tensed brings out the fact that we may define EP using tensed sentences. But, notice, this is not trivial. 'Presence is existence' is an identity claim. And it is not an identity claim with which the eternalist can agree. Consider, by way of example, the Battle of Hastings. If presence is existence then by simply existing the Battle of Hastings is present. The Battle of Hastings is not present and so eternalists cannot endorse EP. EP is not obviously false. It is not at all obvious that presence is not existence. Whereas the claim that only present objects have existed, exist, and will exist, is clearly false, there are no obvious counter examples to EP.

So, EP is neither trivial nor obviously false. But the view is still only very thinly characterised. My intention, for the remainder of this latter part of the paper, is to offer some remarks in hopes of elucidating existence presentism. In the sub-section that follows I will outline two competing theories of existence and show how to accommodate EP within such accounts of existence. In the sub-section that follows on from that, I outline a further account of existence and suggest-rather more tentatively - a way in which EP could be made to fit with this latter account of existence. My hope in arguing in this way is to show that EP does not wed itself to any of the competing accounts of existence. I conclude that, whatever way one thinks about existence, there is a way to make sense of existence presentism.

\footnotetext{
15 The view proposed is perhaps similar to that proposed by Craig (1997). However, Craig thinks that we should not treat existence and presence as a property-I'm more permissive, here, and allow that we could. Further, Craig claims that we should treat presence as a mode of existence (1997: 37). I'm not quite sure what a 'mode of existence is'. Charitably, one might take the view that the conception of existence articulated in Sect. 3.3 is an elaboration on Craig's proposal. In any case, unlike Craig (1997: 37), I do not see that we should endorse a timeless mode of existence. See Sect. 3.5.
} 


\subsection{On Two Notions of Existence}

In Sect. 2.1, I noted two different accounts of existence. The first, the more orthodox Lewisian/Quinean account; the second, a more controversial account, due to McGinn. Let us remind ourselves of these positions in order that we may see more clearly how to understand EP. First, let us turn to the Lewisian notion of existence. I borrow heavily, here, from Van Inwagen (2008). As we have already seen in Sect. 2.1, according to the Quinean orthodoxy, existence is what is expressed by terms like 'there is', 'there are', and so on. ${ }^{16}$ This orthodoxy is compatible with the following kind of claim, that I quote at length:

you can say that existence is a property of you want to. No harm in it. If existence is a property, it is the property something has if and only if it exists, if and only if there is such a thing as it. That is, just as wisdom is the property that corresponds to the open sentence " $\mathrm{x}$ is wise", existence is the property that corresponds to the open sentence "x exists", and that open sentence is logically equivalent to this one: "There is something that is $\mathrm{x}$ ". If you want to talk in that way, however, you should keep it firmly in mind that existence, so conceived, is a wholly uninteresting property.

This 'wholly uninteresting property' of existence is, or so I claim, the exact same property as the property of presence. To deliberately mis-quote Van Inwagen: presence is the property that corresponds to the open sentences ' $\mathrm{x}$ exists' and ' $\mathrm{x}$ is present' - and those sentences are logically equivalent to this one: there is something that is $x^{\prime}$.

Does the fact that presence is then an uninteresting property threaten EP in some way? It's hard to see why it should. It remains true that no non-presentist could endorse this view for according to no other view does an object qualify as present merely by existing. So it cannot be the case, according to other views, that presence is the property that corresponds to the open sentences ' $x$ exists' and ' $x$ is present'.

The view espoused by McGinn, and described in Sect. 2.1, is straightforward to reconcile with EP. According to McGinn, existence is a primitive and unanalysable property of some objects - though not all. This property is, according to the account that I am offering, identical to the property of presence. Once more, I can see no obvious problems with this reconciliation.

Where matters get harder, however, is when we turn our attention to a third theory of existence. According to this view-a view that we may describe as broadly Fregean and Russellian-to say of some objects, the Os, that ' $\mathrm{O}$ exists' means the same thing as 'there are Os'. What both of these expressions mean is, quite simply, that 'something falls under the concept 'the Os'-in more abstract terms still, 'O-hood is exemplified'. 17

Van Inwagen notes that there is a degree of similarity between this account and the account of existence that I am describing as the Quinean account. But although there is a degree of similarity, there is scope for difference, too.

\footnotetext{
16 See, e.g., Van Inwagen (2008: 37).

17 See, Van Inwagen (2008: 37).
} 
As noted above, there is nothing obviously objectionable with thinking of 'existence' as expressing a property if we endorse the Quinean view, but the Frege/Russell view is often thought to exclude existence being a property. (At least, the Frege/Russell view is thought to exclude existence from being a firstorder property of concrete particulars; Russell seems to have treated existence as a property of propositional functions and Frege appears to have treated existence as a property of concepts. ${ }^{18}$ )

Matters here are complex. Some think that the Frege/Russell view is the same (to the extent that existence is not a property) as the Quinean view. Others do not think that the Frege/Russell view is the same as the Quinean view. ${ }^{19}$ If the two views are identical and existence cannot be thought of as a property, then it is unclear how to understand EP. Likewise, if the Frege/Rusell view is not the same as the Quineean view, to the extent that existence can be thought of as a property on the latter view, though not the former, then I still owe an account of how to make sense of EP given the Frege/Russell view of existence.

The focus of the next sub-section of the paper is to demonstrate how to understand EP if existence is not taken to be a property-I do not comment further on whether or not we should treat the Quinean view as the same as the Frege/Rusell view. $^{20}$

\subsection{Existence Presentism Without a Property of Existence}

In this section I will first discuss ontological categories and then discuss truthmaking. I should reinforce my claim that these elucidations of EP are not intended as competing definitions-commentators on early drafts mistook my intentions and so it is as well to flag, precisely, what is going on in the material that follows. The purpose of this sub-section is to get clear on what we might mean by the claim that 'existence is presence' if there is no property of existence.

The first claim that I will make is that the ontological category 'present entity' is identical to the category 'existing entity'. On the assumption that categorical schemes are intended to describe the deep metaphysical structure of reality, the identification of these two categories allows us a non-trivial definition of presentism. In order to make the definition more accessible to those who do not find such talk of ontological categories conducive, I go on to provide an account of how to understand the view in terms of truth-maker theory.

Categorical schemes are commonplace in metaphysics, although this is not always made obvious. Indeed, one might be forgiven for taking the view that although those explicitly endorsing an Aristotelian tradition where categories take centre stage (e.g. Lowe 1998) are engaged in category theory, those that eschew the Aristotelian tradition are not. But I think that this impression would be false. One can very straightforwardly point to categories in the work of those not following in

\footnotetext{
18 See, e.g., Katzav (2008: 487).

19 See, Van Inwagen (2008: 38).

20 Though as Van Inwagen (2008: 38) notes, there are some obvious-albeit minor-differences.
} 
an explicitly Aristotelian tradition. The early Lewis can be described as endorsing a two-category ontology: concrete particulars and sets. ${ }^{21}$

It is typical, though by no means necessary, for each categorical scheme to include a super-category; a category within which all other categories fall. So, on a Chisolmian metaphysics, we have a variety of ontological categories. At the 'bottom' of the categorical system we have boundaries, substances, events, attributes and substance. These, in turn, each fall within other ontological categories: individuals, states and non-states. These are then either contingent or necessary. However, there is then a top-level. The most fundamental level to this category system: Entia. [cf. Westerhoff's (2005: 14) presentation of Chisolm's categories]. Every other ontological category falls within this category. This is what I shall call the 'super category'.

The category metaphysic espoused by Jonathan Lowe is similar, in that it too includes a supercategory, with various other categories falling under it. In Lowe's case, the supercategory is: 'Entity'. ${ }^{22}$ Now, it is an obvious corollary of something's qualifying as an 'Entity' that it also exist. Properly speaking, the super category of 'entity' is the category 'Existing Entity'. It just so happens that what the term 'existing' is redundant given the background assumption that only existents can hope to qualify as entities.

These remarks can then be deployed in order to get clear on precisely what is meant by claiming that existence is presence. To understand EP in terms of category theory is simply to say that the category of existing objects is identical to the category of existing objects. On such a view, EP amounts to a claim about the categorical structure of reality and, according to this account, EP is the view that the way of being that is existing is identical to the way of being that is being present.

\subsection{EP and Truth-Maker}

I don't claim, here, to be offering a different account to that offered in Sect. 3.3. Rather, remarks in this section should be thought of as another way to make sense of EP. There are those who are not particularly fond of thinking about metaphysics in terms of category theory. If we could make sense of the ideas expressed in Sect. 3.3 by using resources from truth-maker theory, that would serve to broaden the accessibility of the theory. For what it's worth, it's also worth keeping in mind the fact that what I say in this section is compatible with each of the other views of existence. Thus, whatever view one takes of existence, provided one also accepts truth-maker theory, there is material here that will help to get traction on the view.

To make sense of what follows, let us assume a presentist-Lowe-style metaphysics of categories. As a consequence of this view, every existing entity in any one of the sub-categories will be a truth-maker for the proposition $<$ there is an entity $>$ (recalling that Lowe's super-category is that of 'entity'). I think that this seemingly trivial fact gives us another way to elucidate what is at the heart of EP.

\footnotetext{
21 Cf. Nolan (2011).

22 For an explication of Lowe's metaphysic, see Lowe (1998). For a nice graphical representation, see Westerhoff (2005: 14).
} 
If an entity, $\mathrm{x}$, is a member of the most general ontological category, $\chi$, then, it serves to 'make true', the claim that ' $\mathrm{x}$ is a $\chi$ '. Thus, as a corollary of this: for any $\mathrm{x}$, $\mathrm{x}$ makes it true that ' $\mathrm{x}$ is present'.

No eternalist can accept this result, for the eternalist thinks that there are entities that exist (more accurately: 'that have existed') without making it true that ' $x$ is present'. To give but a few examples: the Battle of Hastings, Julius Caesar, and Elvis Presley are all entities that exist, according to the eternalist, but do not thereby make it true that they are present entities. It is not true that 'Julius Caesar is present', after all.

It is, therefore, a commitment of EP that:

For all $\mathrm{x}, \mathrm{x}$ makes-true the proposition 'x exists now'; this has always been

true, is true, and always will be true

To be clear, I think that, all of the verbs in the above are tensed. Consider: 'makes' in the above, is present-tensed. In that case, we are committed to $\mathrm{x}$ now 'doing something', and that this is done by every $\mathrm{x}$. That is not possible if $\mathrm{x}$ is nonpresent. Non-present entities cannot do anything now. It is therefore no bar to the forgoing as an illustration and elucidation of EP that 'makes' is present-tensed.

\subsection{Problems and Replies}

In this - the final substantive section of the paper-I consider two concerns with the proposal. The first concern is with the fact that given EP all objects will exist in time-including abstract objects. The second concern surrounds a potential circularity in the explication of the property of presence.

\subsubsection{Timeless Objects and EP}

Here is a worry for EP. If the broadest category of existence is present existence, then it follows that every object that exists-whether physical or abstract-exists presently. That seems an odd and rather extreme commitment. After all, if they exist, objects such as numbers, propositions and their kin seem to be abstract and it is a hallmark of such abstract objects that they exist timelessly-or outside time. Does this present a problem for the proponent of EP?

I don't think that it does. There are two salient lines of argument, here. The first line of argument is an offensive measure that aims to call into question the sense of speaking of objects 'existing outside time'. The second line of argument is defensive.

First, the offense: for much of the paper I've argued that we have two readings of 'exist' - present-tensed and a disjunction of past, present and future-tensed. Given only these two readings, I struggle to see that we can speak of objects that 'exist outside time' at all. Thus the objection rests upon the mistaken claim that one can make sense of talk of 'existing outside time'.

To get to the heart of the concern we need only consider only a present-tensed case. (I think that it's easy enough to see how the arguments presented will extend to the past and future-tensed cases.) Suppose we say, then, that 'abstract objects exist ${ }_{n}$ 
outside time'. Of course, to exist ${ }_{\mathrm{n}}$ is to exist now and to 'exist outside time' is not to exist now. The statement simply makes no sense.

So the offense is this. We started with a worry that EP commits us to there not being objects that exist outside time. It turns out, however, that we may well lack the resources to talk about such objects, anyway. If that's right, then the objection cannot be coherently stated. Tentatively, then, I think that we have a reason to give up on the claim that objects 'exist' outside time. This certainly seems a natural consequence of the discussion of tense that has gone before.

Second, let us consider a potential defense of EP. Suppose that such things as abstract objects do exist. It seems (again, tentatively) that the proponent of EP may simply endorse the view that such objects are changeless, but presently existing, objects. By virtue of existing unchanging at all times, abstract objects are-in $a$ sense-timeless. But on this reading of what it is to be timeless, abstract objects get to be timeless whilst also existing, presently, at each time. The view, though revisionary, seems reasonable. Certainly, it's a little hard to see why the proponent of EP may not adopt such a view.

\subsubsection{Circularity and Presence}

One of the ways of characterising EP that I gave was in terms of properties: I said that we might choose to identify the property of presence with the property of existence. This statement of the view required us to make an existence claim: the property of presence is the property of existence. Of course, this statement of the view is present-tensed: the property of presence is now the property of existence. This, we might worry, threatens a problem. I have said that presence is now existence and that presence is a property. Focus, then, on the property of presence. I have seemingly given something like a definition of the property of presence using the term 'present'. I am thereby committed to my definition of presence being circular. What to say?

I think that the charge of circularity is apt. But I do not think that this is a problem. The proposal at the core of EP is that we offer the same treatment of the property of presence as we do the property of existence. It is hard see how we may explicate either the concept or property of existence without positing a primitive and unanalysable property. As Lowe (1998: 137-138) describes the conception of existence, 'to say that $\mathrm{x}$ exists is just to say that there is something identical with $\mathrm{x}$ '. Thus, to speak of 'the existence of $\mathrm{x}$ ' is simply to talk of there being something identical with $\mathrm{x}$. Lowe, here, is not speaking of a property of existence, but the concept of existence. But we can extent this thought views of existence, like the property view.

The account of existence that treats it as a property is not reductive. But it is not intended to be reductive. If we are to define or characterize the property of 'existing' we will have to do so in at least some part by recourse to talk of 'being' (if we assume no distinction between existence and being) or 'existing'. So be it. Some concepts and some properties will have to be primitive on a metaphysical model and the property of existence-if there is such a property-may well be one of them. Indeed, such is the extent to which existence is a basic element of any metaphysical 
system, it would be something of a surprise were such a property not primitive and undefinable.

Now, according to EP, presence and existence are one. Equally, then, it may well simply be the case that just as we cannot offer a full, complete and non-circular characterization of the property of existence, we cannot offer a full, complete and non-circular characterization of the property of presence. So be it. ${ }^{23}$ But this is not a new cost. We've already said that we cannot characterize the property in a noncircular fashion.

So, let us suppose that presence is to be a fundamental, primitive property. In positing such a property, EP is no worse off than the property view of existence. ${ }^{24}$

\section{Concluding Remarks}

Nothing seems more certain to any agent than that when they exist, they are presentwhenever they are located in time. ${ }^{25}$ This is partly what motivates many people to believe presentism in the first place. It is precisely that close connection between how we think about presence and how we think about existence that inspires the thought that everything that exists, exists now. We gesture at this in the presentist slogan-a slogan avowed by friend (Bigelow 1996) and foe (Sider 2001: 21) alike, to be deeply intuitive - that 'only present objects exist'. By then enshrining in EP the thought that existence is presence we preserve the heart of what motivates presentism.

Open Access This article is distributed under the terms of the Creative Commons Attribution License which permits any use, distribution, and reproduction in any medium, provided the original author(s) and the source are credited.

\section{References}

Armstrong, D. (2004). Truth and truthmakers. Cambridge: CUP.

Bigelow, J. (1996). Presentism and properties. Philosophical Perspectives, 10, 35-52.

Button, T. (2006). There's no time like the present. Analysis, 66, 130-135.

Button, T. (2007). Every now and then, no-futurism faces no sceptical problems. Analysis, 67, 325-332.

Craig, W. L. (1997). Is presentness a property? American Philosophical Quarterly, 34, $27-40$.

Crisp, T. (2004a). On presentism and triviality. In D. Zimmerman (Ed.), Oxford studies in metaphysics (Vol. 1, pp. 15-20). Oxford: OUP.

Crisp, T. (2004b). Reply to Ludlow. Oxford Studies in Metaphysics, I, 37-46.

Crisp, T. (2005a). Review of the ontology of time. Notre Dame Philosophical Reviews. http://ndpr. nd.edu/news/24544-the-ontology-of-time/.

Crisp, T. (2005b). Presentism and cross-time relations. American Philosophical Quarterly, 42, 5-17.

\footnotetext{
${ }^{23}$ Of course, there remains the option for the proponent of EP to drop the characterizations of the view that appeal to properties. I don't take a stand on this issue, here.

24 Indeed, the reasons leveled by Craig (1997: 36) for not treating presence as the property of existence is that the property view of existence suffers from various challenges. Craig may be right. The purpose of the second part of this paper is not to defend any one version of EP, but to show that the basic thesis- that existence is presence - can be rendered compatible with any view of existence. Determining the cogency of these views of existence is not an aim of this paper.

25 See, for discussion, remarks in Button (2006, 2007).
} 
Katzav, J. (2008). The second-order property view of existence. Pacific Philosophical Quarterly, 486-496.

Kierland, J., \& Monton, B. (2007). Presentism and the objection from being supervenience. Australasian Journal of Philosophy, 85, 485-497.

Lewis, D. (1992). Critical notice. Australasian Journal of Philosophy, 70, 211-224.

Lombard, L. B. (2010). Time for a change: A polemic against the presentism-eternalism debate. In J. C. Campbell, M. O’Rourke, \& H. S. Silverstein (Eds.), Time and identity (pp. 49-78). Camb, Mass: MIT Press.

Lowe, E. J. (1998). The possibility of metaphysics. Oxford: Clarendon.

Markosian, N. (1993). How fast does time pass? Philosophy and Phenomenological Research, 53, 829-884.

Markosian, N. (2004). A defense of presentism. Oxford Studies in Metaphysics, 1, 47-82.

McGinn, C. (2000). Logical properties. Oxford: OUP.

Merricks, T. (2007). Truth and ontology. Oxford: OUP.

Meyer, U. (2005). The presentist's dilemma. Philosophical Studies, 122, 213-225.

Mumford, S. (2005). The true and the false. Australasian Journal of Philosophy, 83, 263-269.

Mumford, S. (2007). Negative truth and falsehood. Proceedings of the Aristotelian Society, CVII, 45-71.

Nolan, D. (2011). Categories and ontological dependence. The Monist, 94, 277-300.

Rasmussen, J. (2012). Presentists may say goodbye to A-properties. Analysis, 72, 270-276.

Rodriguez-Preyera, G. (2005). Why truthmakers? In H. Beebee \& J. Dodd (Eds.), Truthmakers: The contemporary debate (pp. 17-31). Oxford: OUP.

Sanson, D., \& Caplan, B. (2010). The way things were. Philosophy and Phenomenological Research, 81, 24-39.

Sider, T. (2001). Four-dimensionalism. Oxford: Clarendon.

Sider, T. (2006). Quantifiers and temporal ontology. Mind, 115, 75-97.

Simons, P. (2005). Negatives, numbers, and necessity: Some worries about Armstrong's version of truthmaking. Australasian Journal of Philosophy, 83, 253-261.

Simons, P. (2008). Why the negations of false atomic sentences are true. In T. de Mey, \& M. Keinänen (Eds.), Essays on Armstrong. Acta Philosophica Fennica. 84, 15-36.

Stoneham, T. (2009). Time and truth: The presentism and eternalism debate. Philosophy, 84, 201-218.

Tallant, J. (2009a). Ontological cheats might just prosper. Analysis, 69, 422-430.

Tallant, J. (2009b). Presentism and truth-making. Erkenntnis, 71, 407-416.

Tallant, J. (2010). Still cheating, still prospering. Analysis, 70, 502-506.

Van Inwagen, P. (2008). McGinn on existence. Philosophical Quarterly, 58, 36-58.

Westerhoff, J. (2005). Ontological categories. Oxford: OUP.

Zimmerman, D. (1996). Persistence and presentism. Philosophical Papers, 25, 115-126. 